\title{
An outbreak of illness among schoolchildren in London: toxic poisoning not mass hysteria
}

\author{
J C Aldous, G A Ellam, V Murray, G Pike
}

\begin{abstract}
Study objective - To determine the cause of an outbreak of acute gastrointestinal illness that occurred shortly after lunch in children attending a school in London, UK.

Design - A questionnaire survey of children at the affected school was carried out on the day after the incident. Microbiological, environmental, and toxicological investigations were also undertaken.

Setting - A school in London, UK. Participants - Altogether 374/468 (80\%) of the children who had eaten lunch at the school on the day of the incident completed a questionnaire.

Main results - There was a significant association between illness and the consumption of raw cucumber (relative risk $=6 \cdot 1 ; 95 \%$ confidence interval $2 \cdot 2,16)$. Microbiological investigation of the foods served at lunch did not show any pathogens and toxicological investigations suggested that the cucumbers were contaminated by a pesticide.

Conclusions - Although the outbreak displayed several typical features of mass psychogenic illness, the most probable cause was a toxic chemical present in cucumber served at lunch. Those responsible for investigating outbreaks of illness should be aware of the possible toxicological causes and the appropriate modes of investigation. They should be wary of too readily attributing a psychogenic cause to unusual outbreaks of acute illness in schoolchildren.
\end{abstract}

( $\mathcal{F}$ Epidemiol Community Health 1994;48:41-45)

Bernard's Wing) Uxbridge Road, Middlesex UB1 3EU

$\mathrm{J}$ C Aldous

Department of Public Health, Riverside Health Authority, London SW6 4UL' G A Ellam

National Poisons Unit, New Cross Hospital, London SE14 5ER

V Murray

Environmental Health Department, Royal Borough of

Kensington and

Chelsea, London

W8 6PW

G Pike

Correspondence to: Dr J C Aldous.

Accepted for publication July 1993

Mass psychogenic illness - also called mass hysteria and mass sociogenic illness - is a well documented cause of epidemics of acute illness. ${ }^{1-16}$ Most published outbreaks have occurred in schools or in the workplace. ${ }^{4111316}$ The cardinal features are the rapid onset and resolution of symptoms, hyperventilation, line of sight transmission, a preponderance of illness in females and the failure to discover a physical or biological aetiological agent. ${ }^{341316}$

We report an unusual outbreak of acute gastrointestinal illness in schoolchildren which displayed several of the typical features of mass psychogenic illness. Detailed investigation, however, clearly suggested that a toxic agent in the food served at lunch was the primary cause of the outbreak.

\section{Background}

On the afternoon of Monday 9 July, 1990, a public health department in London, UK was informed that more than 50 children suffering from acute gastroenteritis had arrived at a hospital emergency department from a local school.

The school was visited the same afternoon. Discussions with teachers showed that the first cases of illness had occurred within half an hour of the children eating lunch at school. Illness had only occurred at four of the seven sites which made up the school; these sites were separated by distances of up to one mile, and each site prepared and served their own meals. A wide range of foods had been available for lunch but the only food that all four affected sites had in common was raw cucumber. It was felt that a number of children, particularly the later casualties, were made to feel ill by the sight of their friends being sick and that some may have exaggerated their illness because they found the idea of an ambulance ride exciting! The school was not residential and lunch was the only meal served that day.

The illness was characterised by abdominal pain, nausea, and vomiting and seemed to be self limiting; all children attending hospital had recovered sufficiently to be discharged home within six hours of the onset of illness.

Because of the rapid onset of symptoms after lunch, possibilities of psychogenic or toxicological causes were considered. The advice of the National Poisons Unit was obtained and further investigations were coordinated through an incident committee composed of the local consultant in communicable disease control, the chief environmental health officer, and a consultant from the National Poisons Unit.

\section{Methods}

A detailed inspection was made of the kitchens and food storage areas at each of the sites. The supplier of each food served at the meals was identified.

\section{EPIDEMIOLOGICAL INVESTIGATION}

Food items eaten at the suspect lunch and symptoms of illness were ascertained through a questionnaire administered at the school on the morning after the incident. Apart from 84 children who had not eaten lunch at school the previous day (and in whom no illness had been reported), all children at the affected sites were requested to complete a questionnaire. In ad-
ENVIRONMENTAL INVESTIGATION 
Table 1 Lunch menus at each affected school site: 9 fuly 1990

\begin{tabular}{ll}
\hline Site & Foods on lunch menu \\
\hline A & Turkey, pizza, cucumber, sliced bread, margarine, apples \\
B & Salami, cheese, cucumber, lettuce, brown and white bread rolls, apples \\
C & Chicken, tomatoes, cucumber, lettuce, white bread rolls, oranges \\
D & Pizza, tomatoes, cucumber, lettuce, bread, butter, carrots, apples \\
\hline
\end{tabular}

dition, to investigate a possible psychogenic cause for the incident, children and staff were interviewed in the week following the outbreak. Data from the questionnaire survey were analysed using Epi-Info Version 5 software. ${ }^{17}$ Multivariate analysis was carried out using the statistical package GLIM. ${ }^{18}$

MICROBIOLOGICAL INVESTIGATION

One sample of vomit from an affected child was obtained and cultured. Stool specimens from eight affected children were sent for bacteriological investigation. Food samples, recovered from plates and dustbins, were also cultured.

\section{TOXICOLOGICAL INVESTIGATION}

A search of published reports and other information sources was carried out to identify toxic agents that might cause similar symptoms. Advice was sought from other poisons centres, from botanists, and from experts from industry. Toxicological and forensic examina-

Table 2 Attack rates by age, sex, and site and consumption of food

\begin{tabular}{lll}
\hline Risk factor & & Attack rates (N1/N2) \\
\hline Sex & Male & $11 \%(28 / 249)$ \\
& Female & $20 \%(25 / 125)$ \\
Site & A & $15 \%(20 / 132)$ \\
& B & $27 \%(20 / 73)$ \\
& D & $3 \%(3 / 98)$ \\
Age group & $5-7$ & $14 \%(10 / 71)$ \\
& $8-10$ & $13 \%(10 / 79)$ \\
Foods & $11-13$ & $18 \%(38 / 206)$ \\
& Cucumber & $6 \%(5 / 89)$ \\
& Apples & $24 \%(49 / 201)$ \\
& Pizza & $18 \%(45 / 250)$ \\
& Lettuce & $11 \%(19 / 81)$ \\
& Sliced bread & $10 \%(15 / 140)$ \\
& Bread rolls & $8 \%(11 / 133)$ \\
All & Tomatoes & $4 \%(3 / 81)$ \\
& & $14 \%(53 / 374)$ \\
\hline
\end{tabular}

Table 3 Attack rates and relative risk (RR) of vomiting with cucumber consumption by age, sex, and site

\begin{tabular}{|c|c|c|c|}
\hline Risk factor & $\begin{array}{l}\text { Attack rate } \\
\text { in exposed } \\
(N 1 / N 2)\end{array}$ & $\begin{array}{l}\text { Attack rate } \\
\text { non-exposed } \\
\text { (N1/N2) }\end{array}$ & $\begin{array}{l}R R \text { of vomiting with cucumber } \\
\text { consumption } \\
(95 \% \mathrm{CI})\end{array}$ \\
\hline $\begin{array}{l}\text { Sex: } \\
\quad \text { Male } \\
\text { Female }\end{array}$ & $\begin{array}{ll}18 \% & (27 / 149) \\
22 \% & (22 / 101)\end{array}$ & $\begin{array}{l}1.0 \%(1 / 100) \\
13 \%(3 / 24)\end{array}$ & $\begin{array}{ll}18 & (2 \cdot 5,131) \\
1 \cdot 7 & (0 \cdot 6,5 \cdot 4)\end{array}$ \\
\hline $\begin{array}{c}\text { Site: } \\
\text { A } \\
\text { B } \\
\text { C } \\
\text { D }\end{array}$ & $\begin{array}{l}21 \%(18 / 84) \\
35 \%(18 / 51) \\
3.8 \%(3 / 80) \\
29 \%(10 / 35)\end{array}$ & $\begin{array}{l}4.2 \%(2 / 48) \\
9 \cdot 1 \%(2 / 22) \\
0.0 \%(0 / 18) \\
0.0 \%(0 / 36)\end{array}$ & $\begin{array}{ll}5 \cdot 1 \quad(1.3,21) \\
3.9(0.98,15) \\
0.7(0.1,6 \cdot 5) \dagger \\
10 \cdot 6(1.4,78) \dagger\end{array}$ \\
\hline $\begin{array}{l}\text { Age group (y): } \\
5-7 \\
8-10 \\
11-13\end{array}$ & $\begin{array}{ll}24 \% & (10 / 42) \\
22 \% & (34 / 154) \\
9 \cdot 3 \% & (5 / 54)\end{array}$ & $\begin{array}{l}0.0 \%(0 / 37) \\
7.7 \%(4 / 52) \\
0.0 \%(0 / 35)\end{array}$ & $\begin{array}{ll}9 \cdot 1 & (1 \cdot 2,67) \dagger \\
2 \cdot 9 & (1 \cdot 1,7 \cdot 7) \\
3 \cdot 3 & (0 \cdot 4,27) \dagger\end{array}$ \\
\hline All & $20 \%(49 / 250)$ & $3 \cdot 2 \%(4 / 124)$ & $6 \cdot 1 \quad(2 \cdot 2,16)$ \\
\hline
\end{tabular}

* Exposed $=$ ate cucumber; non-exposed $=$ did not eat cucumber.

+ No cases occurred in non-exposed group. Relative risk calculated by placing 1 case in zero cell. tion was carried out on cucumbers remaining at the affected sites and on cucumbers purchased locally as control samples. Methods included thin layer chromatography, high performance liquid chromatography, $x$ ray microanalysis, and atomic absorbtion spectrophotometry.

The nursery which supplied the cucumbers to the affected sites was traced and inspected, and samples of cucumbers submitted for toxicological analysis.

\section{Results}

ENVIRONMENTAL INVESTIGATION

The foods served for lunch at each site are given in table 1. Cucumber was the only food served at all four sites. Foods served at more than one site included apples (three sites), lettuce (three sites), pizza (two sites), sliced bread (two sites), white bread rolls (two sites), and tomatoes (two sites).

Each of the four sites affected by illness were found to have received their fruit and vegetables from the same supplier. The three unaffected sites had obtained their food from a different supplier.

\section{EPIDEMIOLOGICAL INVESTIGATION \\ Questionnaires}

Altogether $374 / 468(80 \%)$ of the children who ate lunch on the day of the incident completed a questionnaire. Their ages ranged from 5-13 years (mean 8.8$)$ and a total of $124(34 \%)$ were girls. Some $129(34 \%)$ children said they became ill on 9 July. Common symptoms included abdominal pain $110(85 \%)$, nausea 96 $(74 \%)$, feeling hot $63(48 \%)$, and vomiting 53 $(41 \%)$. Only $15(12 \%)$ suffered from loose stools.

A case was defined as any child attending the affected sites of the school who vomited on 9 July 1990 . The overall attack rate was $14 \%$ (53 cases). Table 2 shows the attack rates by sex, school site, age group, and consumption of food. Only those foods that were eaten at more than one site have been included.

For the whole cohort, children who had eaten cucumber had a significant risk of becoming cases (relative risk $=6 \cdot 1 ; 95 \%$ confidence interval $(\mathrm{CI})=2 \cdot 2,16)$. Stratified analyses showed that the strength of the association between cases and cucumber consumption varied with both sex, school site, and age (table 3 ).

The associations between cases and the consumption of those foods that were served at more than one site were determined using the combined cohorts from each of the sites where that food had been on the menu. No significant positive associations were found. Using logistic regression, a main effects model was fitted to evaluate the risk of becoming a case in relation to age, sex, consumption of cucumber, and school site. Cucumber consumption, site, and sex all seemed to have a significant main effect on the risk of becoming a case. The effect of cucumber consumption on the risk of becoming a case remained highly significant 
$(\mathrm{p}<0.0001)$ after adjusting for the other variables and interactions. Table 4 shows the risk estimates by sex, school site, and consumption of cucumber. Overall, the relative risk of becoming a case with cucumber consumption was $27.5(95 \% \mathrm{CI}=3 \cdot 6,212)$ in boys and $2 \cdot 23$ $(95 \% \mathrm{CI}=0 \cdot 6,8 \cdot 5)$ in girls.

\section{Interviews with staff}

Several cases of illness had occurred at three affected school sites before the teachers there were aware of illness at any of the other sites. One of the sites was situated within a military barracks with restricted access, making communication with children at other sites after lunch virtually impossible.

\section{Interviews with children}

Thirty seven cases were interviewed in depth one week after the incident. Only $7(19 \%)$ children could recall being told that there might be something wrong with the food before they became ill. Ten $(27 \%)$ children said that they had neither seen someone else being sick nor heard anyone complaining of illness before they themselves became ill. Three $(8 \%)$ claimed that they had not eaten cucumber. The remainder had eaten a significant amount of cucumber ranging from 1-9 large pieces (average 3.5). Only four (11\%) said that the cucumber tasted unusual; they described the taste as sour, sharp, or tangy. The children complained of a variety of symptoms other than nausea, vomiting, and abdominal pain. The commonest were: dizziness $(40 \%)$, sore or dry throat $(23 \%)$, headache $(20 \%)$, itchy or prickly skin $(11 \%)$, and blurred vision (11\%). Most children had recovered completely by the day after the incident but a few complained of continuing mild symptoms of nausea and abdominal pain.

\section{MICROBIOLOGICAL INVESTIGATION}

There was no bacterial growth from the sample of vomit. Staphylococcus aureus was cultured from four of the eight stool samples submitted but phage typing showed that they were all of different strains. No food poisoning organisms were detected in samples of

Table 4 Multivariate analysis: relative risks ( $R R$ ) of illness by sex, school site, and cucumber consumption

\begin{tabular}{llll}
\hline Sex & $\begin{array}{l}\text { Cucumber } \\
\text { consumption }\end{array}$ & School site & $R R^{*}$ \\
\hline Male & Yes & A & 14 \\
& & B & 39 \\
& & C & $3 \cdot 3$ \\
& No & D & $6 \cdot 4$ \\
& & B & $0 \cdot 5$ \\
& & C & $1 \cdot 4$ \\
Female & Yes & D & $0 \cdot 12$ \\
& & A & 423 \\
& & B & 30 \\
& No & D & $0 \cdot 01$ \\
& & A & $3 \cdot 9$ \\
& & B & 19 \\
& & C & $0 \cdot 005$ \\
& & D & $1 \cdot 5$ \\
\hline
\end{tabular}

* Risks calculated relative to hypothetical child: age $=5$ sex $=$ male; site $=A$; no cucumber consumption. cucumber, apples, lettuce, tomatoes, and turkey.

\section{TOXICOLOGICAL INVESTIGATION}

Investigations focused on possible non-microbiological, toxic agents in the cucumber. These could be of two sorts: substances naturally present in the food or chemical contaminants.

In some circumstances cucumbers may biosynthesise natural toxins called cucurbitacins. The reported effects of these substances are similar to strychnine intoxication and quite different from those reported in this outbreak. ${ }^{19}$ However, a band in the ultra violet spectrum of material obtained from thin layer chromatography of an extract of suspect cucumber was similar to that of cucurbitacin derivatives. This band was not present in control cucumbers. Therefore the possibility that cucurbitacins were responsible for the illness could not be completely excluded. Analyses also indicated the presence of an alkaloid which could not be identified.

Of the chemicals approved for use on cucumber in the UK, a few (namely some organophosphates, carbamate pesticides, and pyrethroids) may cause gastrointestinal illnesses, but the children did not display the usual pattern of illness due to poisoning by any of these substances. The literature search, however, showed reports of incidents of food poisoning by cucumbers and watermelons, with some similarities to the illness in this outbreak, caused by contamination by the carbamate pesticide, aldicarb..$^{201}$

The inspection of the nursery which supplied the cucumbers to the affected sites showed that they were grown in a rockwool hydroponic system and were treated with a fungicide containing the active ingredient, imazalil, and various fertilisers. No evidence of the use of aldicarb was found. The water supply to the farm was not investigated.

Laboratory analyses of cucumbers for pesticides were therefore restricted to detecting aldicarb (as its metabolite aldicarb sulphoxide (ASO)) and imazalil, the only pesticide reported to have been used in the nursery.

Analysis of cucumbers from the school detected a peak in the high performance liquid chromatogram appropriate for ASO. This was not present in control cucumbers. Although this could not be regarded as definitive evidence for the presence of this pesticide metabolite since no reference sample could be obtained for comparison, it strongly supported the possibility of aldicarb contamination.

Imazalil was not detected in the samples of cucumber from the schools but was found in the cucumbers from the nursery at a concentration of $0.03 \mathrm{mg} / \mathrm{kg}$. There is little knowledge of the toxicity of imazalil in humans but it was thought that this level would be unlikely to cause illness.

Other possible contaminants that might cause a similar illness include copper sulphate, zinc and other elemental metals, detergents and fluoride. All of these would have given an 
obvious colour or taste, or both, to the contaminated food and $x$ ray microanalysis and atomic absorbtion spectrophotometry of the suspect cucumbers showed no evidence of foreign elements or heavy metal contaminants. Examination of samples of cucumber by light microscopy showed no evidence of tampering.

\section{Discussion and conclusions}

Three possible causes of the outbreak need to be considered: mass psychogenic illness, microbial contamination of food, and chemical contamination of food.

At first sight, the rapid onset and resolution of symptoms, the higher attack rate in girls, the anecdotal evidence of psychogenic illness, and the fact that cucumber, the only food that was served in all four affected sites is very rarely associated with outbreaks of food borne disease, all suggested mass psychogenic illness. ${ }^{411316}$ Detailed investigation, however, showed this to be an unlikely diagnosis. Transmission of mass psychogenic illness invariably occurs by line of sight or verbal communication. In this outbreak, illness occurred simultaneously in different sites of the school, with neither teachers nor schoolchildren being aware of illness at other sites. Bizarre symptoms, often with evidence of overt hyperventilation, together with recurrences of illness after an initial outbreak have often been reported in outbreaks of mass psychogenic illness. In this outbreak, symptoms were fairly uniform and no new cases of illness were reported in the days after the outbreak despite local and national media reports of a "mystery illness" at the school.

Two features of the outbreak strongly suggest that a toxic agent ingested at lunch initiated the incident. Firstly, the affected sites had all received their fruit and vegetables (including cucumber) from the same grower and supplier, whereas foods consumed at the unaffected sites came from a different supplier. Secondly, epidemiological investigations showed a strong association between illness and the consumption of cucumber.

Was this association valid? Non-response bias could have led to a spurious association if response rates had been independently associated with both illness and cucumber consumption. Although there is some suggestion that response rates may have varied with illness, several teachers thought that a few of the most severely affected children had stayed away from school the following day. This bias is unlikely to have been significant as only four of $28(14 \%)$ cases identified from the hospital attenders had failed to complete a questionnaire. Also it is difficult to envisage how the response rate could be independently associated with cucumber consumption.

Significant information bias in the ascertainment of case status is also unlikely as this information was validated by examining hospital records and interviews with cases.

Information bias over whether or not a child had eaten cucumber could have occurred. The fact that cucumber was the only food eaten at all the affected sites - and hence was a likely culprit - was recognised by the headmaster in conversations with the investigating team on the evening of the outbreak. Although it is unlikely that any children had made a similar deduction by the time they completed the questionnaire, it is possible that a few of the teachers may have done so and thus influenced the recording of cucumber consumption - especially in the younger age groups who needed their teacher's help to complete the questionnaire. Although such a bias is a distinct possibility, it is unlikely to have been responsible for such a strong association between illness and cucumber consumption. The association between illness and cucumber consumption was only strong and significant in the boys, although girls were more likely to have become ill than boys. One possible explanation, backed up by anecdotal evidence from staff at the school, is that a secondary wave of psychogenic illness accounted for some of the later cases among girls, thereby diluting the strength of the association.

There are certain aspects of this outbreak that we would have liked to have investigated further: the presence of a dose-response relationship between cucumber consumption and vomiting; the low attack rate in site $C$; and more extensive microbiological investigations. We were hampered, however, by the fact that the outbreak occurred on the last week of the school term. By the time we had the results of the initial questionnaire, suggesting that cucumber was the culprit, many children (especially those who had become ill) stopped attending the school either because of the outbreak (and resulting media publicity) or because it was the last week of term.

The onset of illness within one hour of eating lunch excludes all known bacterial agents other than the preformed enterotoxins of Staphylococcus aureus and Bacillus cereus. ${ }^{2223}$ Both agents may cause a similar pattern of illness to this outbreak although a higher incidence of vomiting and diarrhoea are usual. ${ }^{22}$ Microbiological investigations failed to show either organism in the food samples, and neither cucumber nor the other foods served at several affected sites are commonly associated with toxin producing microbiological contamination. ${ }^{2223}$

Although toxicological and forensic investigations failed to identify definitively an aetiological agent, the results support the possibility of aldicarb poisoning. It is interesting to compare this outbreak with five reported incidents of food poisoning from cucumbers or watermelons contaminated with the pesticide, aldicarb. ${ }^{2021}$ The illness described in these incidents was similar to that in this outbreak in that it was rapid in onset, gastrointestinal symptoms were prominent, and most victims recovered quickly and completely without any specific medical treatment. Aldicarb sulphoxide, a metabolite of aldicarb, was found in samples of melons or cucumbers in each of the outbreaks, and estimates of the dosages of ASO that had caused illness in individuals ${ }^{21}$ have suggested that people could have become 
ill after ingesting produce contaminated with ASO at levels below the detection limit of 0.2 parts per million. More recently, there have been reports of an outbreak of illness in Eire caused by cucumbers contaminated with aldicarb. ${ }^{24}$

Aldicarb is a widely used pesticide and able to persist in the ground water. When dissolved in water it is taken up by the roots of cucumbers and other cucurbitaceae such as melons and deposited in the fruit. This pesticide, however, is not approved for use on cucumbers either in the United States or in Britain. In the 1987 California incident, a melon was taken from a field where melons were being grown for seed and aldicarb was being applied legally, but it is probable ${ }^{21}$ that in the other incidents the cucumber growers had kept aldicarb on the premises to treat ornamental plants and there had been employee error or greenhouse pest problems, or both, leading to its misuse.

We conclude that the cause of the outbreak was a toxic chemical, most probably aldicarb, present in cucumber served at lunch. A secondary wave of psychogenic illness may have occurred after the initial outbreak. Investigators should be alert to possible toxicological causes of outbreaks of acute illness. Toxicological investigations require considerable expertise in elucidating possible causal agents and in the correct collection and storage of specimens. Advice should be sought early from local poisons units. Investigators should beware of too readily attributing a psychogenic cause to unusual outbreaks of acute illness in schoolchildren.

We wish to thank Mr Matthew Hickman, Dr Akhtar Khakoo, and the environmental health officers of the Royal Borough of Kensington and Chelsea, London for their help in the investKensington and Chelsea, London for their help in the invest-
igation. We are most grateful for the help of Ms Heather Wation. We are most grateful for the help of Ms Heather
Wiseman of the National Poisons Unit, and Ms Jane Bruce,
Senior Statistician at the PHLS Communicable Disease Surveillance Centre. We thank Reading Scientific Services Limited for performing the forensic and toxicological investigations.

1 Moss PD, McEvedy CM. An epidemic of overbreathing among schoolgirls. BMF 1966;2:1295-300.

McEvedy CM, Griffith A, Hall T. Two school epidemics. BMF 1966;2:1300-2.

3 Editorial. Epidemic hysteria. BMF 1979;2:408-9.

4 Levine RJ. Mass hysteria. Arch Intern Med 1984;144:1945-

5 Smith HCT, Eastham EJ. An outbreak of abdominal pain Lancet 1973;ii:956-8.

6 Levine RJ. Epidemic faintness and syncope in a schoo marching band. $\mathcal{F} A M A$ 1977;238:2373-6.

7 Wason S, Baucher JC. Epidemic "mass" hysteria. Lancet 1983;ii:731-2.

8 Levine RJ, Sexton DJ, Romm FJ, et al. Outbreak of psychosomatic illness at a rural elementary school. Lancet 1974;ii:1500-3.

9 Ruiz MT, Lopez JM. Mass hysteria at a secondary school Int $\mathcal{F}$ Epidemiol 1988;17:475-6.

10 Philen RM, Kilbourne EM, McKinley TW, et al. Mass sociogenic illness by proxy. Lancet $1989 ;$ ii:1372-6.

11 Boxer PA. Occupational mass psychogenic illness. f Occup Med 1985;27:867-72.

12 Modan B, Swartz TA, Tirosh M, et al. The Arjenyattah epidemic. Lancet 1983;ii:1472-4.

13 Centers for Disease Control. Mass sociogenic illness at a day care centre. MMWR 1990;39(18):301-3.

14 Landrigan PJ, Miller B. The Arjenyattah epidemic. Lance 1983;ii: $1474-6$.

15 Small GW. Outbreak of illness at a school chorus. Toxic poisoning or mass hysteria. $N$ Engl $\mathcal{f}$ Med 1983;308(11):652-5.

16 Sirois F. Epidemic hysteria. Acta Psychiatr Scand 1974;252(Suppl):1-46.

17 Dean AG, Dean JA, Burton AH, Dicker RC. Epi-Info Version 5: a word processing, database and statistics program for epidemiology on microcomputers. Georgia, USA USD Incorporated, 1990.

18 Healy MJ. GLIM - an introduction. Oxford, UK: Oxford University Press, 1988.

19 Rehm S. Poisonous vegetables. Spectrum 1966;4:423-6.

20 Goes EA, Savage EP, Gibbons G, Aaronson M, Ford SA Wheeler HW. Suspected foodborne carbamate pesticide intoxications associated with injestion of hydroponic cucumbers. Am ₹ Epidemiol 1980;111(2):254-60.

21 Goldman LR, Beller M, Jackson RJ. Acute food poisonings in California, 1985-1988: toxicity estimates for humans. Arch Environ Health 1990;45(3):141-7.

22 Hughes JM, Tauxe RV. Food borne disease. In: Mandell GL, Douglas R, Bennett JE, eds. Principles and practice of infectious disease. New York: Churchill Livingstone, infectious disease.

23 Holmberg SD, Blake PA. Staphylococcal food poisoning in the United States: new facts and old misconceptions. the United States: new
$\mathfrak{f} A M A 1984 ; 251: 487-9$.

24 Stinson J, O'Gharabhain F, Adebayo G, Chambers P, Feely J. Pesticide contaminated cucumber. Lancet 1993;341:64. 